\title{
Development of Flax oil-based Biopolymer for Biocomposites
} S. Panigrahi, X. Li, S. Panigrahi, R. L. Kushwaha

\author{
College of Engineering, University of Saskatchewan, 57 Campus Drive, Saskatoon, SK, S7N 5A9 Canada
}

H.N.Dhakal

Department of Mechanical and Design Engineering, University of Portsmouth,

Copyright (c) 2009 SAE International

Anglesea Building, Anglesea Road, PO1 3DJ, U.K

\begin{abstract}
Flax oil is the main goal of growing flaxseed. Flax oil has been used for nutrition, food, paint binder, putty, and wood finish. However, synthetic resin from flax oil has not been developed. In this paper we will develop a biopolymer derived from flax oil and the goal is to use it as a resin to produce a viable, biodegradable composite using natural fiber as reinforcement. First, the functionalization of the triglyceride group of the flax oil fatty acids with polymerizable chemical groups was studied. The triglyceride molecule of flax oil was epoxidized by the reaction of double bonds in the fatty acid with a peroxy acid (formic acid) to get epoxidized oil; the epoxidized oil was then reacted with ethylenically substituted carboxylic acid (acrylic acid) to form acrylated epoxidized flax oil. Polymer resins were prepared from flax oil by blending acrylated epoxidized flax oil with styrene and a free radical initiator. The characterization of developed polymer and the intermediates during processing were investigated. This technology will add value to flax oil by converting it to a bio-based resin for industrial use, which will offer significant opportunities for new, improved materials from renewable resources.
\end{abstract}

Keywords: Flaxseed oil, Bio-based resin, Characterizaiton, FTIR, DSC

\section{INTRODUCTION}

Polymers are traditionally made from petroleum. A new trend existing today is that petroleum-derived raw materials are replaced with renewable plant-based raw materials. One example is soybean oil-derived resin, which has been shown both economically and socially attractive and the development of such resin contributes to global sustainability by preventing the depletion of scarce resources (Lu et al. 2005).

Natural plant oils are predominantly made up of triglyceride molecules. The triglyceride contains many active sites amenable to chemical reactions, such as the double bond, the allylic carbons, the ester group, and the carbon alpha to the ester group. These active sites can be used to introduce polymerizable groups on the triglyceride, similar to the synthesis of petroleum-based polymers. The key step is to reach a high molecular weight and cross-linked density, as well as to incorporate chemical groups that are known to impart stiffness in a polymer network (Wool and Sun 2005). Several synthetic pathways have been found to accomplish this, where the double bonds of the triglyceride are used to functionalize the triglyceride with polymerizable chemical groups.

Flax is produced for its natural plant oil rich seed. Flax oil (or known as linseed oil, flaxseed oil) has been widely used as a carrying agent for paints, varnishes, lacquer, and printing ink. Unfortunately these markets have eroded somewhat over the years with the production of synthetic resins and latexes. 
Most common oils contain fatty acids that vary from 14 to 22 carbons in length, with 0 to 3 double bonds per fatty acid (Khot et al 2001). Soybean is the most common resource to be used to make polymers. The compositions of flaxseed oil compared with soybean oil are shown as Table 1. Refined soybean oil is composed of $99 \%$ triglycerides (Lu et al. 2005). Flaxseed (e.g.: No.1 of Canada) has $44.7 \%$ oil and $24.3 \%$ protein (DeClercq 2007a). In flax oil, the three unsaturated fatty acid side chains consist primarily of alpha linolenic acid (C18: 3), linoleic acid (C 18: 2) and oleic acid (C18: 1).

Table 1. Fatty acid composition of Canadian flaxseed and soybean for 2007 harvest survey (DeClercq 2007a, DeClercq 2007b).

\begin{tabular}{llll}
\hline $\begin{array}{l}\text { Fatty acid, } \\
\text { \% in oil }\end{array}$ & $\begin{array}{l}\text { Double } \\
\text { bonds }\end{array}$ & $\begin{array}{l}\text { Flaxseed } \\
\text {, No. 1 }\end{array}$ & Soybean \\
\hline Palmitic (C16:0) & 0 & 5.0 & $9.5-10.3$ \\
Stearic (C18:0) & 0 & 3.6 & $3.9-4.9$ \\
Oleic (C18:1) & 1 & 20.6 & $19.7-25.0$ \\
Linoleic (C18:2) & 2 & 16.2 & $49.1-55.1$ \\
Linolenic (C18:3) & 3 & 52.6 & $6.9-10.4$ \\
\hline
\end{tabular}

Most common oils contain fatty acids that vary from 14 to 22 carbons in length, with 0 to 3 double bonds per fatty acid (Khot et al 2001). Soybean is the most common resource to be used to make polymers. The compositions of flaxseed oil compared with soybean oil are shown as Table 1. Refined soybean oil is composed of $99 \%$ triglycerides (Lu et al. 2005). Flaxseed (e.g.: No.1 of Canada) has $44.7 \%$ oil and $24.3 \%$ protein (DeClercq 2007a). In flax oil, the three unsaturated fatty acid side chains consist primarily of alpha linolenic acid (C18: 3), linoleic acid (C 18: 2) and oleic acid (C18: 1).

From the natural triglyceride, it is possible to attach maleinates or convert the unsaturateded bonds to epoxies or hydroxyl functionalities. Such transformations make the triglyceride capable of reaction via ringopening or polycondensation polymerization (Wool and Sun 2005). These particular chemical pathways are also accessible by attaching vinyl functionalities to the epoxyand hydroxyl-functional triglycerides. Reaction of the epoxy-functional triglyceride with acrylic acid incorporates acrylates onto the triglyceride, or reaction of the hydroxylated triglyceride with maleic anhydride incorporates maleate half-esters and esters onto the triglyceride (Wool and Sun 2005). By blending them with a reactive diluent, similar to most conventional vinylester resins, and cured by free-radical polymerization, resin can be made.

Epoxidized triglycerides can be found in natural oils, such as vernonia plant oil (Khot et al. 2001). They can also be synthesized from unsaturated oils, such as soybean oil or linseed oil. These oils are used as plasticizers in polyvinyl chloride in place of phthalates or as toughening agents (Khot et al. 2001). With the addition of acrylates, the triglyceride can be reacted via addition polymerization to form acrylated epoxidized oil. For instance, AESO has been used in the area of surface coatings and ink applications (Khot et al. 2001).

The addition of styrene to modified epoxidized oil or any type of unsaturated polyester is common practice to synthesis resin. Styrene has the chemical formula of $\mathrm{C}_{6} \mathrm{H}_{5} \mathrm{CH}=\mathrm{CH}_{2}$. Because of its vinyl group with a double bond, it can polymerize to form plastics resin. "Its low cost and low viscosity improves the price and processability of the resin" (Khot et al. 2001). It also imparts rigidity to triglyceride-based polymers which the triglyceride does not naturally possess.

Another method for synthesizing monomers from triglycerides is to reduce triglycerides to monoglycerides through glycerolysis or amidation reactions. But these reactions require high temperatures $\left(230^{\circ} \mathrm{C}\right)$ as compared to ring-opening and polycondensation polymerization reactions (around $80^{\circ} \mathrm{C}$ ) (Khot et al. 2001). The third method is to functionalize the unsaturation sites and reduce the triglyceride into monoglycerides (Wool and Sun 2005). The method is glycerolysis of an unsaturated triglyceride, followed by hydroxylation or glycerolysis of a hydroxyl functional triglyceride. The monomer can react with maleic anhydride, forming a monomer capable of polymerization by the free-radical mechanism (Wool and Sun 2005).

In this paper, resin is synthesized from flaxseed oil and the chemical characterization during synthesizing is studied. This is a new trial to develop a resin from Canadian flaxseed oil. Flax oil has the potential to synthesize resin due to their composition. However, the studies in this area have not yet been developed. Therefore, the results presented here, form a useful basis for future research on the development of resins and plasticizers from flax oil and their use in composites and other applications in biomaterials.

\section{MATERIALS AND METHODS}

\section{MATERIALS}

Organic flaxseed oil (Herbal Select, Guelph, ON) was purchased from the local market, which is $100 \%$ pure cold-pressed flax oil. Formic acid (85\% M=46.03/mol) and styrene were purchased from Sigma-Aldrich. Acrylic acid (Mallinckrodt Baker, Inc. Phillipsburg, NJ) and sodium chloride (A Johnson Mathey Company, Ward Hill, MA) were used. Hydrogen peroxide (30\% solution), sodium bicarbonate, and sodium sulfate are from EMD Chemcials Inc. Gibbstown, NJ. Hydrogen peroxide (3\% 
solution) and ethyl ether were purchased form VWR International, West Chester, PA.

\section{SYNTHESIS}

Synthesis of epoxidized flax oil (EFO) -Flax oil was mixed with hydrogen peroxide (30\%) and formic acid (85\%) in a weight ratio of 50: $45: 17$. The mixture was stirred at $25^{\circ} \mathrm{C}$ for 17 hours. This step generates the epoxidized flax oil. Then the epoxidized flax oil was dissolved in ether and washed with saturated sodium bicarbonate solution until the $\mathrm{pH}$ reached neutral. The mixture was washed with saturated sodium chloride solution and dried over sodium sulfate. The oil and water phase were separated using a separating funnel. The washing step is necessary to remove the residual hydrogen peroxide and formic acid from the epoxidized oil (Khot et al. 2001). The ether was removed by heating the oil to a temperature of $40^{\circ} \mathrm{C}$.

Flax oil was also mixed with hydrogen peroxide (3\%) and formic acid (85\%) in a weight ratio of 50: 374: 18. The mixture was stirred at $25^{\circ} \mathrm{C}$ for 17 hours. The oil and water phases were separated using a separating funnel.

Synthesis of acrylated epoxidized flax oil (AEFO) and resin - Epoxidized flax oil was mixed with acrylic acid in a the weight ratio of $1: 3$. The mixture was stirred at $70^{\circ} \mathrm{C}$ for 4 hours. The acrylated epoxidized flax oil was blended with styrene in a weight ratio of 100:45. The resin was then cured at a temperature of $90^{\circ} \mathrm{C}$ for 1 hour and $110^{\circ} \mathrm{C}$ for 2 hours. Different mixing weight ratios (styrene : AEFO) and curing times $\left(90^{\circ} \mathrm{C}\right.$ for 1 hour and $120^{\circ} \mathrm{C}$ for 1 to 2 hours) has been investigated.

\section{CHARACTERIZATION}

Fourier transform infrared spectroscopy (FTIR) - The oil and modified oil samples were characterized by JASCO FT/IR-4000 Spectrometer (JASCO, Easton, MD) using potassium bromide $(\mathrm{KBr})$ cells. A small drop of sample was placed on the plate so as to form a thin film. By interpreting the infrared absorption spectrum, the chemical bonds in a molecule can be determined.

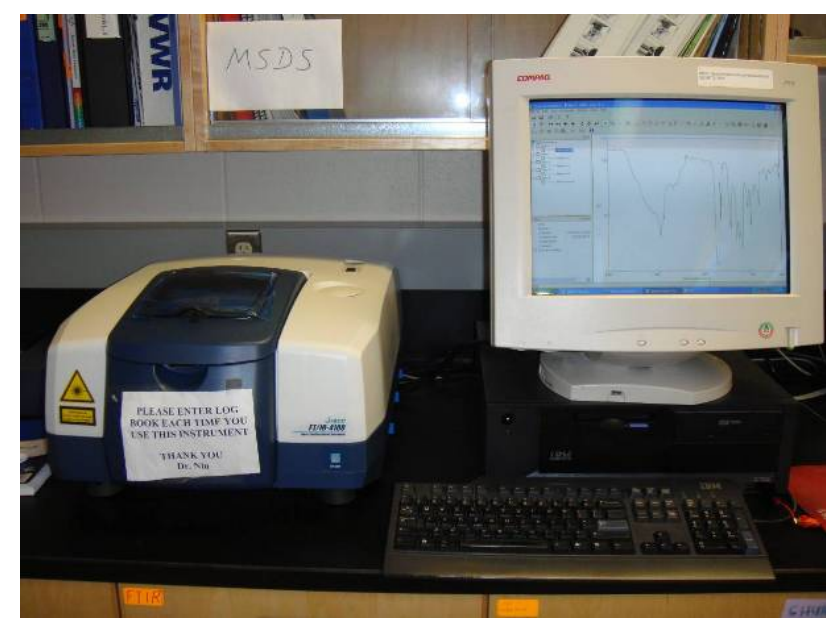

Figure 1. The JASCO FT/IR-4000 Spectrometer.

Viscosities - The kinematic viscosities of oil samples were measured using Cannon-Fenske Viscometer in accordance with the ASTM D446-00 method. CannonFenske Routine Viscometer with sizes of 400 and 300 were used. The kinematic viscosity of oil samples was measured at a temperature of $25^{\circ} \mathrm{C}$. Dynamic viscosity was calculated by density multiple kinematic viscosity.

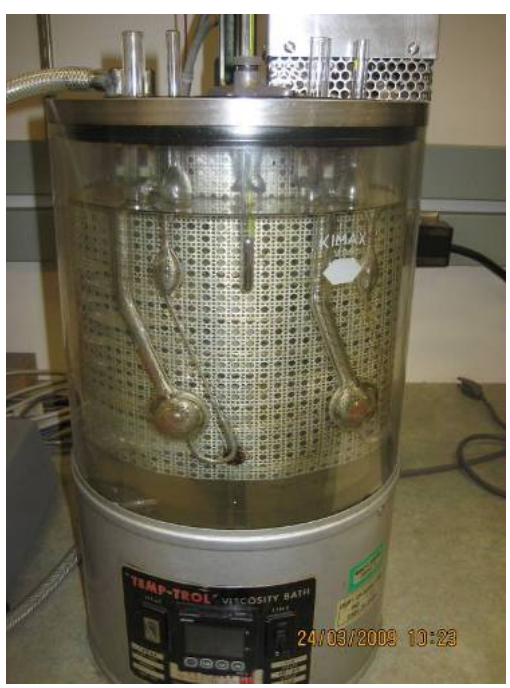

Figure 2. Cannon-Fenske Viscometer

DSC - Thermal characterization of resin was tested by DSC Q2000 (TA Instruments). Five to $10 \mathrm{mg}$ of sample was weighed and run between a temperature range of 30 to $400^{\circ} \mathrm{C}$ with the heating rate set to $5^{\circ} \mathrm{C} / \mathrm{min}$. 


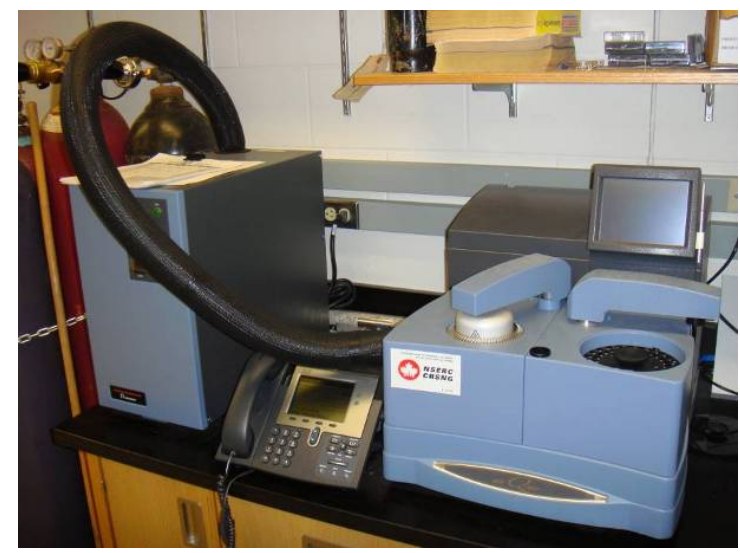

Figure 3. DSC Q2000 (TA Instruments).

\section{RESULTS AND DISCUSSION}

\section{SYNTHESIS OF EFO}

The major component in natural oil is triglyceride. As seen from the composition of flaxseed in table 1 , triglyceride in flax seed composed of double bound acid: alpha linolenic acid (C18: 3), linoleic acid (C 18: 2) and oleic acid (C18: 1). The formula of triglyceride in flaxseed oil can be shown in Figure 4.

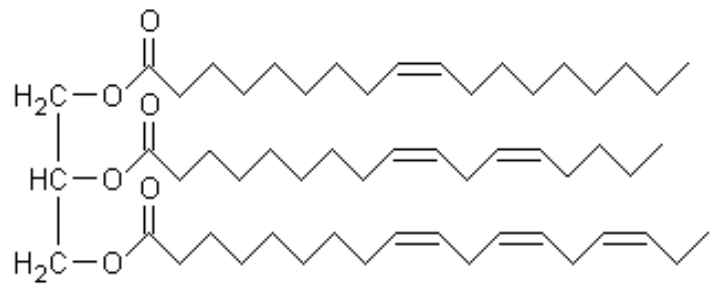

Figure 4.Flax oil triglyceride molecule.

To help understand the composition, the FTIR spectrum of flax oil is given in Figure 5. The pair of peaks observed at 2855 and $2925 \mathrm{~cm}^{-1}$ is from $\mathrm{CH}_{2}$. The peak at $1746 \mathrm{~cm}^{-1}$ corresponds $\mathrm{C}=\mathrm{O}$ stretching. The double bonds $=\mathrm{C}-\mathrm{H}$ and $\mathrm{C}=\mathrm{C}$ stretching are at peaks $3010 \mathrm{~cm}^{-1}$ and $1653 \mathrm{~cm}^{-1}$.

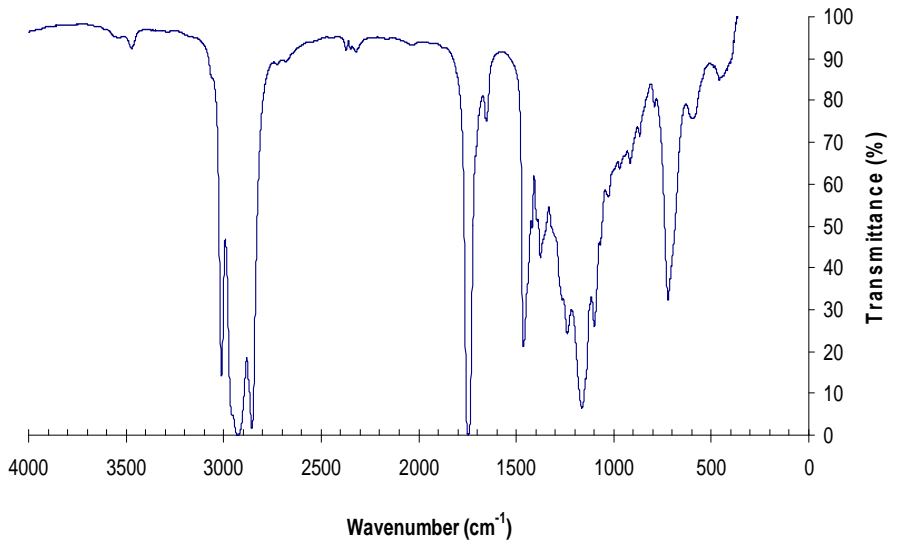

Figure 5. FTIR spectrum of flax oil

Epoxidized flax oil was synthesized by blending flax oil with formic acid $(\mathrm{HCOOH})$ and $\mathrm{H}_{2} \mathrm{O}_{2}$. This reaction is to break the double bonds in the fatty acid with formic acid. The reaction can be explained more clearly by the molecule formula change given by Woo and Sun (2005), in which they explained the synthesis of epoxidized soybean oil as given in figure 6 , where the double bonds of $\mathrm{C}=\mathrm{C}$ are open and epoxy groups are formed.
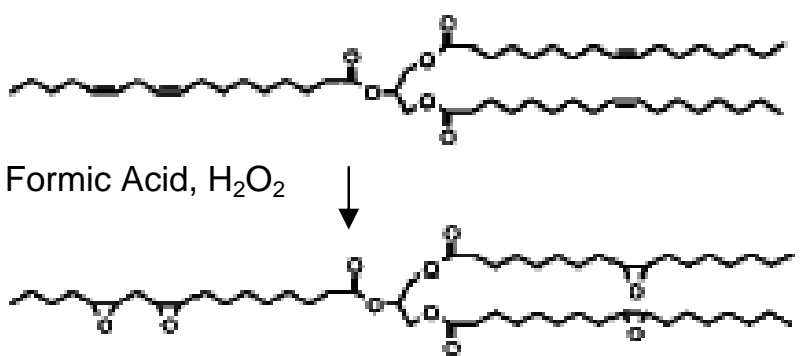

Figure 6.Triglyceride of the soybean oil and epoxidized triglyceride molecule.

The FTIR spectrum of epoxidized flax oil is given in figure 7. Compared with flax oil (Figure 5), the disappearance of double bonds $\left(=\mathrm{C}-\mathrm{H}, 3010 \mathrm{~cm}^{-1}\right)$ and $\mathrm{C}=\mathrm{C}$ stretching $\left(1653 \mathrm{~cm}^{-1}\right)$ in EFO and the formation of epoxy groups $\left(822 \mathrm{~cm}^{-1}\right)$ were monitored during the synthesis by an FTIR spectrometer. The graph is as expected.

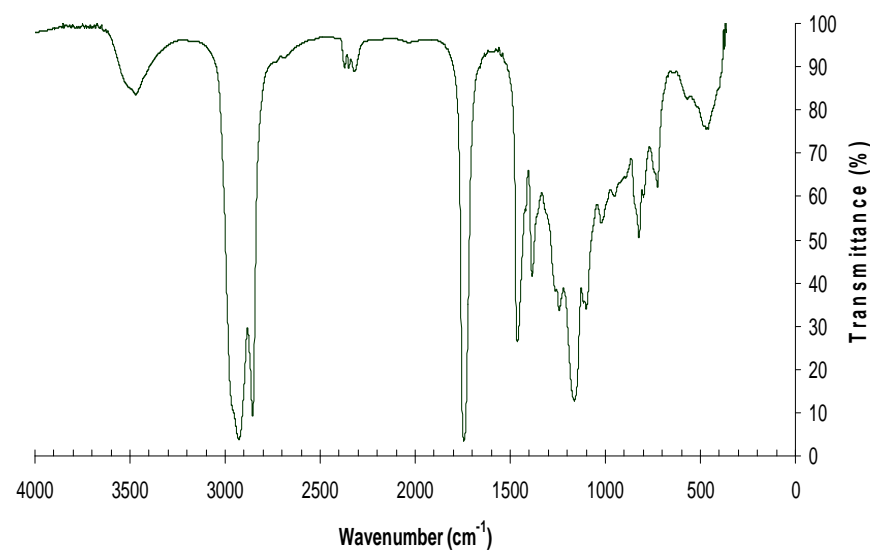

Figure 7. FTIR spectrum of epoxidized flax oil (EFO) from method 1.

The epoxidized flax oil (EFO) made from hydrogen peroxide (3\%) and formic acid (85\%) was also studied through FTIR and the result is shown in figure 8. However, there is not difference in the two FTIR spectra, for flax oil and for EFO. This may be because the concentration of $\mathrm{H}_{2} \mathrm{O}_{2}(3 \%)$ is too low, which means that not only is the epoxy acid functioned with the triglyceride molecule, but also the concentration of $\mathrm{H}_{2} \mathrm{O}_{2}$ is important to help opening the double bond of triglyceride molecule and format epoxy groups. 


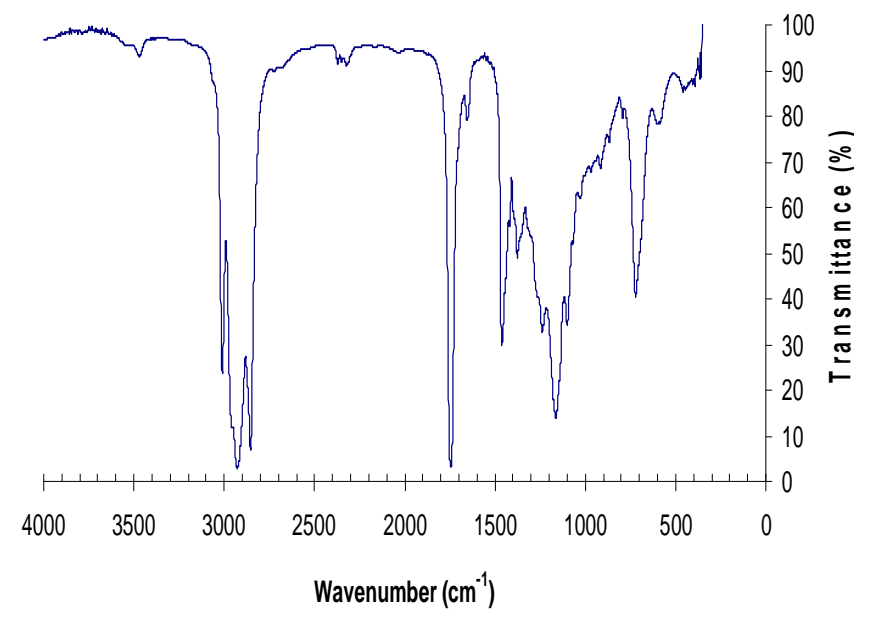

Figure 8. FTIR spectrum of epoxidized flax oil (EFO) from hydrogen peroxide with low concentration (3\%).

The density and viscosity of flax oil and epoxidized flax oil were measured and the results are shown in table 2 . Both density and viscosity of EFO are higher than flax oil. This may be caused due to the change in molecular weight, polarity, and intermolecular forces ( $\mathrm{Wu}$ et al. 2000): "the epoxidized oils have high molecular weight and more polar structure than the original oil; consequently, the interactions between molecules would be stronger".

Table 2. Density and viscosity of flax oil and epoxidized flax oil from method 1

\begin{tabular}{llll}
\hline $\begin{array}{l}\text { Propertie } \\
\mathrm{s}\end{array}$ & $\begin{array}{l}\text { Density } \\
\left(\mathrm{kg} / \mathrm{m}^{3}\right)\end{array}$ & $\begin{array}{l}\text { Dynamic viscosity } \\
25^{\circ} \mathrm{C}(\mathrm{Pa} . \mathrm{s})\end{array}$ & at \\
\hline Flax oil & $896.7 \pm 50.2$ & $0.0413 \pm 0.0027$ & \\
EFO & $925.6 \pm 55.3$ & $0.1972 \pm 0.0126$ &
\end{tabular}

Note: \pm standard deviation

\section{SYNTHESIS OF AEFO}

The AEFO can be introduced acrylate functional group by reacting with acrylic acid $\left(\mathrm{CH}_{2}=\mathrm{CHCOOH}\right)$. The reaction scheme for acrylated epoxidized (soybean oil) triglyceride molecule is given by Woo and Sun (2005) as shown in figure 9.
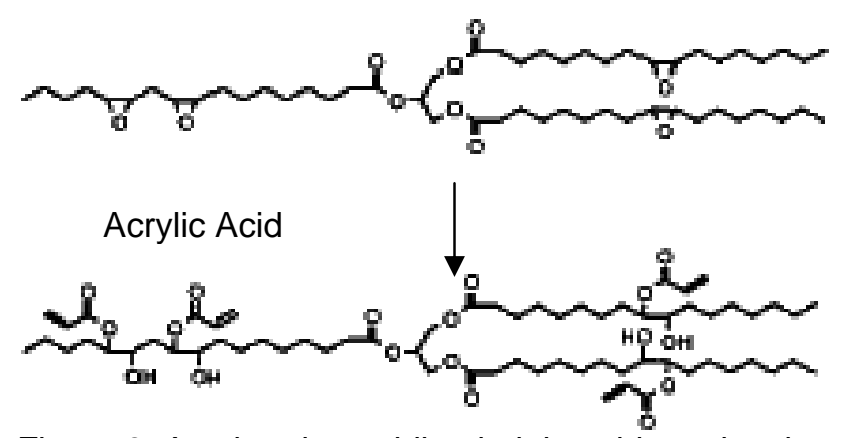

Figure 9. Acrylated epoxidized triglyceride molecule.
The FTIR spectrum of AEFO is shown in figure 10. The broad and weak peaks from 2500 to 2800 are the stretching of $-\mathrm{OH}$ group. The peaks of 1617 and $1635 \mathrm{~cm}^{-1}$ observed in spectrum of AEFO are obviously different from spectrum of EFO. This is in the stretching zone of $\mathrm{C}=\mathrm{C}$, standing the introduction of $\mathrm{H}$ group.<smiles>C=C(C)C</smiles>

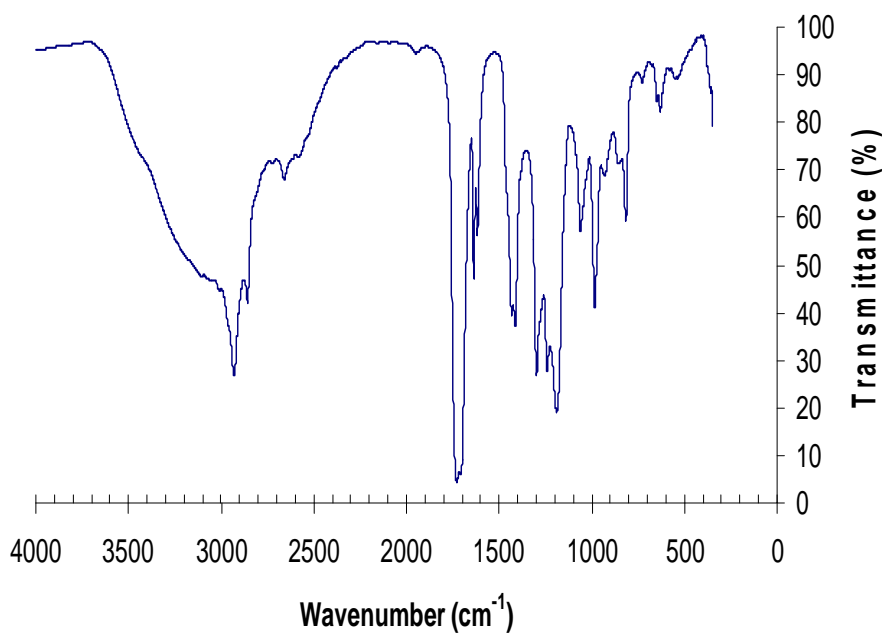

Figure 10. FTIR spectrum of acrylated epoxidized flax oil (AEFO) from method $A$.

The density and viscosity of AEFO are measured as shown in Table 3 . The density of AEFO is higher than that of flax oil and EFO. But the viscosity of AEFO is less than both flax oil and EFO.

Table 3. Density and viscosity of flax oil and epoxidized, acrylated epoxidized flax oil

\begin{tabular}{lll}
\hline Properties & $\begin{array}{l}\text { Density } \\
\left(\mathrm{kg} / \mathrm{m}^{3}\right)\end{array}$ & $\begin{array}{l}\text { Dynamic viscosity } \\
\text { at } 25^{\circ} \mathrm{C}(\mathrm{Pa} . \mathrm{s})\end{array}$ \\
\hline AEFO & $1074.4 \pm 16.5$ & $0.0039 \pm 0.0002$ \\
\hline
\end{tabular}

Note: \pm standard deviation

It was also found that at temperature higher than 80$90^{\circ} \mathrm{C}$, the acrylic acid and EFO formed the white foam quickly. The same phenomenon is also observed when EFO mixed with acrylic acid at temperature of $125^{\circ} \mathrm{C}$. Bonnaillie and Wool (2007) made foam with pressurized carbon dioxide from acrylated epoxidized soybean oil and its fatty acid monomers. Hence, foam can be formed at high temperature, which is another application of flax oil in polymers.

\section{SYNTHESIS OF BIOPOLYMER}

The AEFO was blended with styrene (styrene: AEFO $=45: 100$ ) and cured at $90^{\circ} \mathrm{C}$ for 1 hour and $110^{\circ} \mathrm{C}$ for 2 hours. The synthesized polymers were studied the thermal characterization temperatures. The DSC scheme of AEFO-based resin is shown in figure 11. 


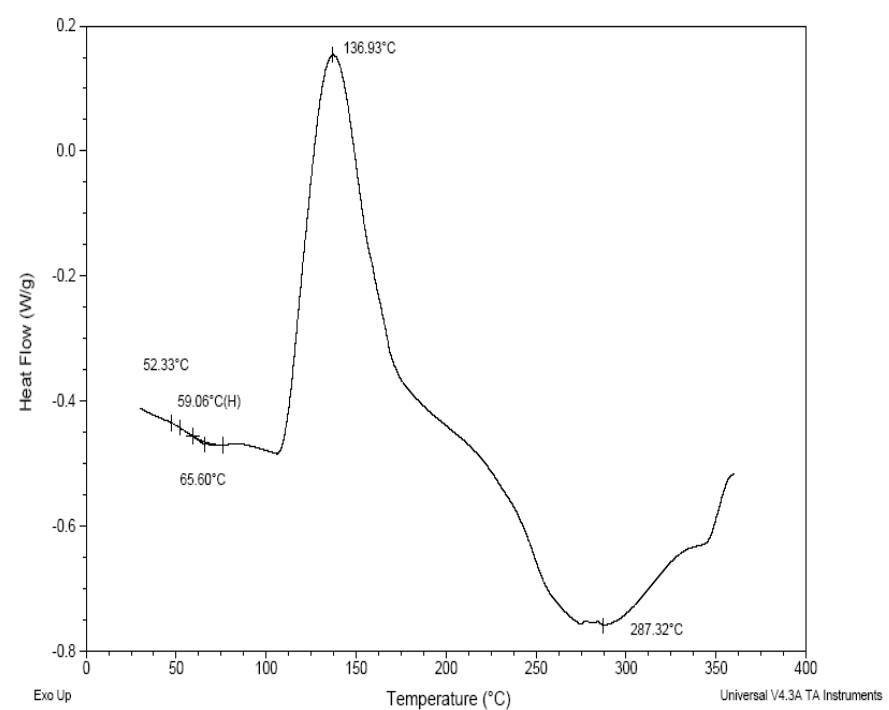

Figure 11. DSC scheme of flax oil-based resin

Glass transition temperature is not very obvious from the DSC curve. It is about $60^{\circ} \mathrm{C}$. As the temperature rises above the glass transition temperature, the polymer becomes more rubber-like. In general, glass transition temperature above room temperature defines rigid and structural polymers. As this transition ended, a positive peak in the DSC curve appears, stands for crystallization temperature. It is observed an obviously crystallization temperature at around $170^{\circ} \mathrm{C}$. A broad region (270$300^{\circ} \mathrm{C}$ ) of melting then began. This process appeared on the DSC curves as a broad endothermic effect.

The cure time has influence on the properties of synthesized resin. Different curing times are investigated in this project. Figures 12 to 14 show the DSC curves of resin at $120^{\circ} \mathrm{C}$ with 1 hour to 2 hours curing time.

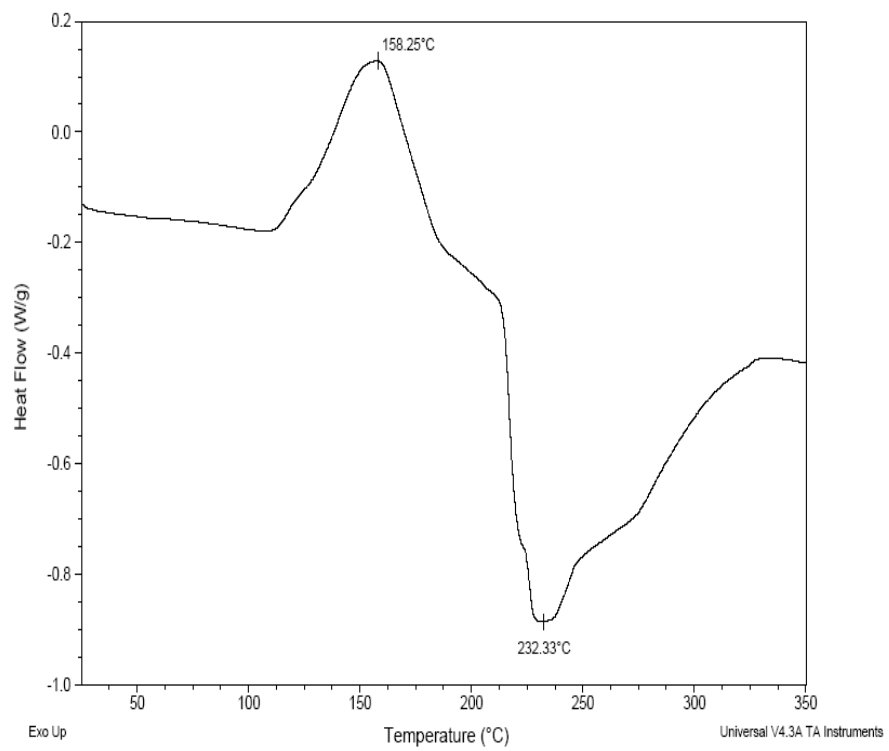

Figure 12. DSC of flax oil-based resin $\left(120^{\circ} \mathrm{C}\right.$ 1hour cure)

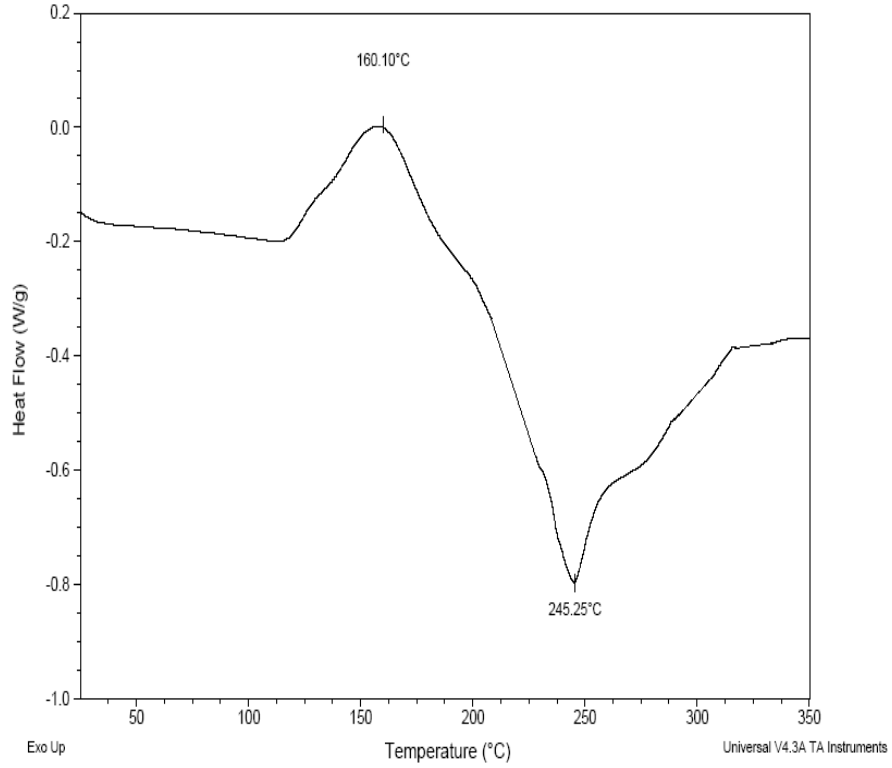

Figure 15. DSC of flax oil-based resin $\left(120^{\circ} \mathrm{C} 1.5\right.$ hours cure)

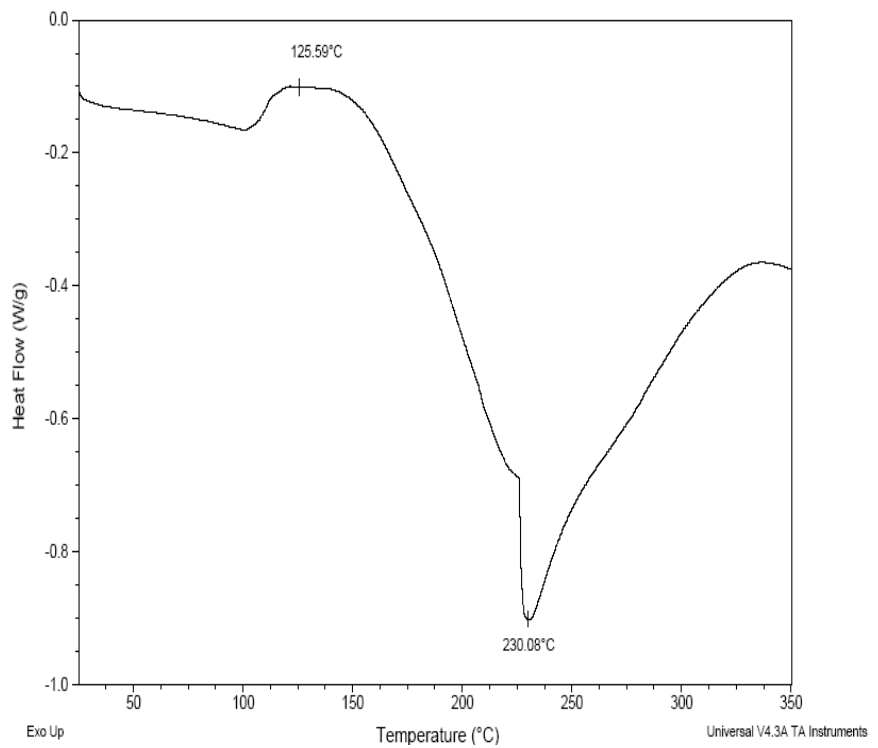

Figure 14. DSC of flax oil-based resin $\left(120^{\circ} \mathrm{C} 2\right.$ hours cure)

The change of glass transition temperature is not obvious from figures 12 to 14 . But the endothermic peak standing for crystallization temperature is weaker with curing time increased. Melting temperature and crystallization temperature increased with time, and then decreased. Curing time of 1.5 hour and at $120^{\circ} \mathrm{C}$ gives the highest melting temperature and crystallization temperature. 


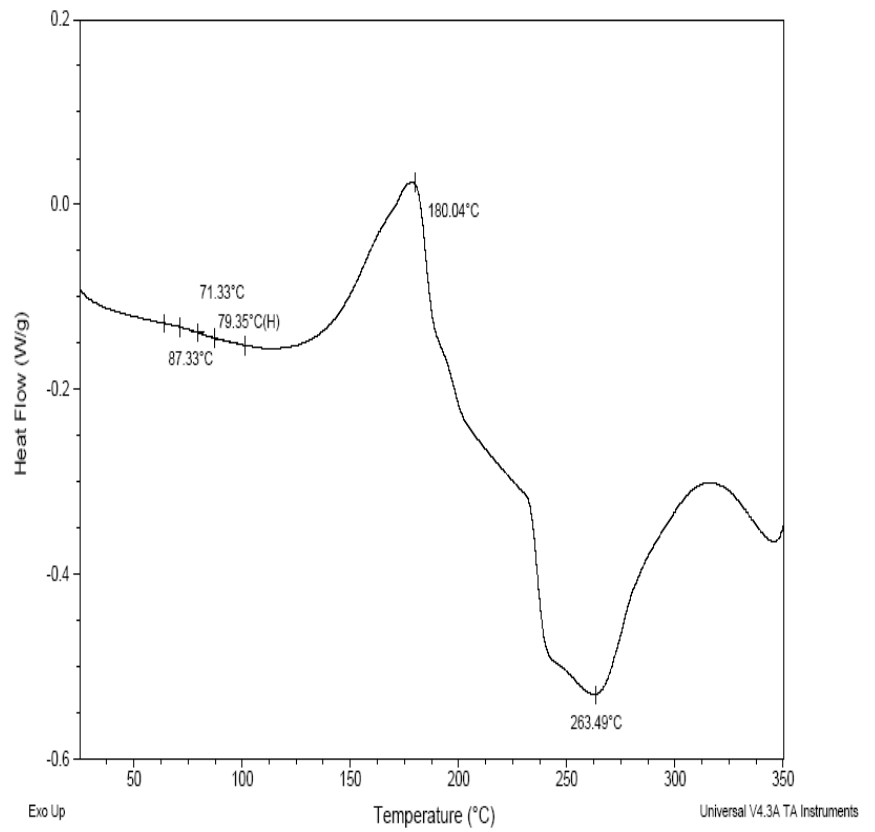

Figure 15. DSC of flax oil-based resin (styrene: $A E F O=$ $1: 3)$

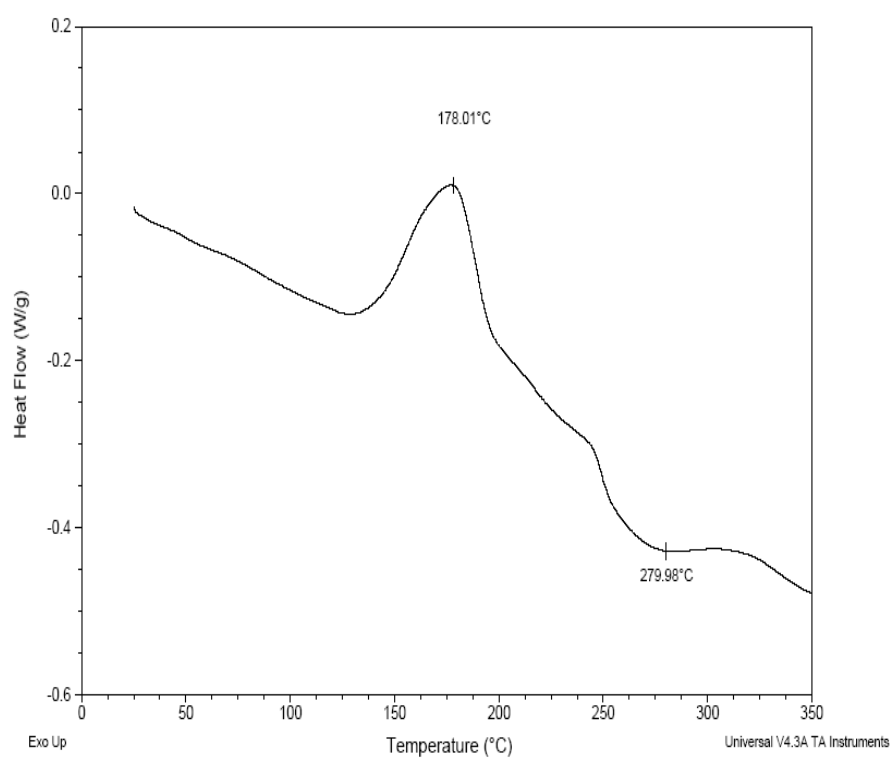

Figure 16. DSC of flax oil-based resin (styrene: $A E F O=$ 3:1)

It is reported that changing styrene concentration in the resin will also change the glass transition temperature and cross-linking properties (Lu et al.2005). However, in our research, with styrene concentration increased (figures 15 and 16), glass transition temperature was not clearly found. It gave a continuously progressing curve as given in figure 16 . With styrene concentration increased, crystallization temperature decreased and a very broad region of melting was observed.

\section{CONCLUSIONS}

Flax is produced for its natural oil rich plant seed. In this project the biopolymer resin derived from flax oil was developed first time for its further using in biodegradable composite.

Triglyceride unsaturation structure of the flax oil was converted to epoxy oil and reacted with acrylic acid to form acrylated epoxidized flax oil, then blended with styrene and cured to form polymer resin. During the reaction, chemical concentration, reacting temperature and time influenced the formation of epoxidized oil and acrylated epoxidized flax oil. The mole fraction and concentration of hydrogen peroxide and formic acid to form epoxidized flax oil have to be kept in a certain ratio, otherwise the double bond of triglyceride can not be opened for future polymerization. The temperature of epoxy oil reacting with acrylic acid should be lower than approximately $85^{\circ} \mathrm{C}$, otherwise, undesired foam formation occurs. The developed polymer resin showed rigid properties and an obvious crystallization temperature. Curing time of 1.5 hour and at $120^{\circ} \mathrm{C}$ gave the highest melting temperature and crystallization temperature. The ratio of styrene to acrylated epoxidized flax oil can be 3 to 1 in mixing to produce polymer resin.

\section{ACKNOWLEDGEMENTS}

The authors would like to acknowledge the Saskatchewan Ministry of Agriculture Research Chair Programs in Engineering, AAFC-ABIP, ADF and NSERC for their financial contributions and supports for this research.

\section{REFERENCES}

Bonnaillie, L. M. and R. P. Wool. 2007. Thermosetting foam with a high bio-based content from acrylated epoxidized soybean oil and carbon dioxide. Journal of applied polymer science 105(3): 1042-1052.

DeClercq, D.R. 2007a. Quality of 2007 Western Canadian Flaxseed. http://www.grainscanada.gc.ca/Quality/Flax/2007/flax2007-eng.pdf

DeClercq, D.R. 2007b. Quality of 2007 Canadian Soybeans.

http://www.grainscanada.gc.ca/Quality/Soybean/2007/so ybean-2007-eng.pdf

Khot, S. N., J. J. Lascala, E. Can, S. S. Morye, G. I. Williams, G. R. Palmese, S. H. Kusefoglu, R. P. Wool. 2001. Development and application of triglyceride-based polymers and composites. Journal of Applied Polymer Science 82(3):703-723. 
Lu, J., S. Khot, and R. P. Wool. 2005. New sheet molding compound resins from soybean oil. I. Synthesis and characterization. Polymer 46: 71-80.

Wool, R. P. and X. S. Sun. 2005. Bio-based polymers and composites. Burlington, MA: Elsevier Academic Press. pp57-111.

\section{CONTACT}

\section{Satya Panigrahi}

E-mail: sap382@mail.usask.ca Tel: 1(306)9665312, Fax: 1(306)966-533 